\title{
Cartografando uma produção de redes vivas do cuidado
}

\author{
Mapping a production of living care networks
}

\author{
Daniele Alves Peixoto e Patrícia Oliveira Lira ${ }^{2}$
}

Resumo: Esse artigo é fruto da dissertação de mestrado que se dedicou às reflexões sobre a produção do cuidado para além da rede de saúde mental institucionalizada. O objetivo principal foi acompanhar o processo de construção dos fluxos de vida e cuidado junto às pessoas que não estavam inseridas em serviços de saúde mental da rede pública. Para tanto, partiu de uma parceria construída com um grupo de ajuda mútuo em uma cidade da Paraíba/PB, voltado às pessoas com Transtorno Afetivo Bipolar (TAB), onde realizou-se o acompanhamento de uma usuária em seu percurso de produção do cuidado. Através da utilização da cartografia, proposta por Deleuze e Guattari, pudemos dar visibilidade à construção de uma Rede Viva de cuidado produzida pela usuária acompanhada. O dispositivo utilizado inicialmente para aproximação com o grupo foi o Acompanhamento Terapêutico (AT) o que permitiu que os encontros acontecessem em diferentes lugares da cidade. O caminhar desse encontro nos permitiu acompanhar a produção da própria rede de cuidados de uma usuária, articulando não só a saúde, mas também lazer e espiritualidade. Propomos o necessário exercício de pensar e problematizar nossas práticas para a contínua construção de uma Reforma Psiquiátrica Antimanicomial, mais ainda: uma sociedade Antimanicomial.

Palavras-chave: Cuidado; Saúde Mental; Reforma Psiquiátrica.

\begin{abstract}
This article is the result of a master's thesis dedicated to reflections on the production of care beyond the institutionalized mental health network. The main objective was to accompany the process of building life and care flows with people who were not included in public health mental services. Starting from a partnership built with a group of mutual help in a city in Paraíba / PB, aimed at people with Bipolar Affective Disorder (TAB), where a user was monitored in her care production path. Through the use of cartography, proposed by Deleuze and Guattari, we were able to give visibility to the construction of a Live Care Network produced by the monitored user. The device initially used to approach the group was Therapeutic Accompaniment (TA), which allowed the meetings to take place in different places in the city. The walk of this meeting allowed us to monitor the production of a user's own care network, articulating not only health, but also leisure and spirituality. We propose the necessary exercise of thinking and problematizing our practices for the continuous construction of an Anti-Asylum Psychiatric Reform, even more: an Anti-asylum society.
\end{abstract}

Keywords: Care; Mental health; Psychiatric Reform.

\footnotetext{
1 Psicóloga. Mestre em Psicologia e Saúde Mental pela Universidade de Pernambuco (UPE). E-mail: danipeixoto89@gmail.com

2 Doutora em Psicologia pela Université Paris-nord (Paris 13). Docente adjunta do Curso de Saúde Coletiva da Faculdade de Ciências Medicas da Universidade de Pernambuco/UPE e Docente permanente do Mestrado Profissional em Práticas e Inovação em Saúde Mental da UPE. E-mail: patricia.lira@upe.br
} 


\section{Introdução}

Esse artigo é fruto da dissertação de mestrado de uma das autoras que buscou refletir sobre a produção do cuidado para além da rede de saúde mental institucionalizada, utilizando o Acompanhamento Terapêutico (AT) como proposta de cuidado-intervenção junto às integrantes de um Grupo de Apoio Mútuo (GAM) na Paraíba/PB, priorizando as pessoas que não estavam sendo atendidas nos serviços da rede de saúde pública.

Esse grupo surgiu do desejo de uma jornalista, diagnosticada com Transtorno Afetivo Bipolar (TAB), em criar um grupo de apoio mútuo entre pessoas que compartilhavam do mesmo diagnóstico que ela. Ao lançar, em 2016, um livro com escritos sobre sua experiência como pessoa convivendo com o TAB, aproveitou a presença da imprensa para convidar as pessoas a participarem das reuniões do grupo de ajuda mútua - que ainda não existia - mas que ela divulgou como um grupo em funcionamento. Disponibilizou seu número de telefone e após isso várias pessoas começaram a entrar em contato querendo participar.

Desde então, o GAM funciona com reuniões aos sábados à tarde. Em todo encontro há um profissional de saúde convidado para debater sobre algum tema referente ao TAB. Esse modelo de funcionamento é inspirado na Associação Brasileira de Familiares, Amigos e Portadores de Transtornos Afetivos - ABRATA, uma associação civil, sem fins lucrativos, com sede na cidade de São Paulo. Na Paraíba, os encontros são os seguintes: roda de conversa sobre algum tema relacionado ao adoecimento, Grupo de Apoio Mútuo apenas para pessoas com o TAB ou depressão (GAM) e um Grupo de Apoio Mútuo aos Sobreviventes do Suicídio (GAMSS). Esses dois últimos têm vagas limitadas e todas as atividades são gratuitas. A finalidade fundamental desses grupos é trocar experiências, compartilhar vivências, buscar soluções e se ajudar de forma solidária, por meio de suporte, apoio e conforto uns aos outros.

Um dos objetivos dessa pesquisa foi o de acompanhar o processo de construção de novos fluxos de vida e de cuidado, através do Acompanhamento Terapêutico, para pessoas do Grupo de Ajuda Mútuo de um município da Parába, que não estavam acessando os serviços de Saúde Mental; e também construir, com os usuários, novos itinerários terapêuticos traçando seus mapas afetivos a partir de seus territórios geográficos e existenciais.

0 Acompanhamento Terapêutico funcionou como um dispositivo para nos aproximar dos integrantes do grupo de apoio mútuo de pessoas com Transtorno Afetivo Bipolar, amigos e familiares com o intuito de observar como o cuidado se operava fora dos muros institucionais. Diante disso, este artigo busca produzir um relato da experiência dos encontros nesse território aberto, tendo uma usuária como a grande provocadora das discussões trazidas. Frida foi o nome escolhido para falarmos de nossa protagonista, por sua capacidade de se reinventar apesar das limitaç̧oes que a vida foil he impondo.

Frida é uma mulher de 32 anos, nascida no interior da Parába em uma família de muitos filhos, biológicos e de criação. Apresenta perda parcial das funç̃oes do membro superior esquerdo devido a uma sequela de traumatismo sofrida durante o parto (Tocotraumatismo). Essa condição física Ihe marca profundamente, pois atravessa todas as suas relaçoes e a constituição de sua história. Foi diagnosticada com Esquizofrenia e com Transtorno Afetivo Bipolar. É curatelada, ou seja, diante da justiça é considerada incapaz de exercer seus deveres enquanto cidadã. Já passou por diversos serviços de saúde mental, tendo sido internada algumas vezes em hospital psiquiátrico. Mora sozinha e em cidade diferente da família devido aos diversos conflitos que já ocorreram entre eles.

\section{Um pouco sobre as redes vivas de cuidado}

As redes de serviços de saúde são pautadas, frequentemente, por uma grande centralidade em suas próprias lógicas de saberes, supervalorizando suas técnicas, protocolos e procedimentos, sobrepondo-se às experiências e conhecimentos que traz o usuário que chega nessa rede. Tomam-se esses sujeitos como objetos da ação do saber que o profissional de saúde considera como mais correto e mais saudável para aquelas pessoas (Merhy, 2004).

Nesse tipo de encontro entre profissional e usuário há um certo olhar para o outro que é sempre previsível, uma previsibilidade que pode acabar produzindo também invisibilidade sobre a produção da multiplicidade de vidas que aquela pessoa traz. Ou seja, é como se fosse solicitado ao usuário que ele deixasse do lado de fora do serviço o seu modo de existência que construiu para si até aquele momento (Merhy et al, 2014).

Entretanto os usuários produzem-se"em-mundos", "in-mundizam-se"e criam para si, através de suas formas éticas existenciais, a sua própria produção de cuidado que está em disputa o tempo inteiro com diferentes formas e lógicas de existir, e que lhe são impostas, muitas vezes, pelas instituiç̄ões (Merhy et al, 2014).

Lancetti (2006) diz que o usuário da saúde mental além de ser um nômade pelas redes de cuidado é também um forte protagonista de sua produçãa. Muitas vezes as equipes de saúde não conhecem esse território que se configura como uma rede rizomática, tomado como produção de agenciamentos, e que não se deixa capturar em um único território (Merhy et al, 2014).

É preciso exercitar um olhar que nos faça ver a dimensão micropolítica para que se consiga captar as experiências cotidianas dos usuários. Ou seja, trazer para a discussão os furos nos muros institucionais, as conexões com o fora, a produção de novos sentidos de viver, a produção viva das redes de conexões existenciais (Merhy et al, 2014).

A possibilidade de promover a ampliação das redes existenciais tem como principal objetivo ampliar os recursos que cada um tem disponível para ir produzindo, isto é, produzir a possibilidade de lançarem mão de leques de opções, de cartas na manga, de vários recursos para ampliar a capacidade de cada um, em suas redes existenciais, irem reinventando as suas existências para enfrentar os vários momentos da vida. A falta de rede de encontros empobrece as possibilidades de mudanças. Quando você se inclui na rede do outro, pode contribuir para novos agenciamentos por ser um a mais destas redes, e não ser a única rede que possibilita a potência do outro. Os sinais que vêm da rua nos convocam a todo instante a um processo de desaprendizagem, do já sabido, do já instituído de nossas velhas práticas para poder apreender novas lógicas produzidas pela perspicácia do viver. (Merhy et al, 2014, p. 159).

Falar dessas redes existenciais é falar em redes vivas. Percebam que há uma diferença do modo como o Ministério da Saúde concebe rede, que écomo algo sólido, inteiro e com extenso controle de governabilidade. Ao contrário, a rede viva diz respeito à produção da vida em si, na qual 0 usuário fabrica o 
cuidado com o seu território existencial, tendo um funcionamento rizomático e em ato, em acontecimento (Merhy et al, 2014).

A Rede Viva é então a construção de redes, forjada pelos usuários em busca da construção de seu cuidado, através das vivências e dos encontros que se efetivam no território. São redes de conexões existenciais. Não é fixa, nem protocolar, nem está dada a priori, não se limita, mas se produz a todo tempo em abertura de conexões com tudo que gera vida. Nesse sentido, cada usuário produz sua própria rede de conexões existenciais, que pode também se entrelaçar com as redes de saúde formais em diferentes momentos e diversas circunstâncias.

É no plano intensivo das redes vivas que o trabalho do AT mais acontece. É no território existencial dos sujeitos, no extra muro institucional que 0 acompanhante terapêutico, através dos encontros, vai tecendo essa rede com os usuários, construindo novos jeitos de andar, de sentir, de pensar, de cuidar, de amar.

Assim, olhar para a produção das redes vivas dos usuários pode nos apontar elementos para pensar o cuidado em saúde como um processo tecido coletivamente e de forma heterogênea, escapando sempre das malhas duras dos protocolos instituídos. Nesse sentido, al guns integrantes do grupo de ajuda mútuo diziam que não estavam frequentando o CAPS, ou seja, não estavam na rede formal de saúde, mas estavam ali no grupo produzindo um certo tipo de cuidado. Nas páginas seguintes narramos o percurso de acompanhar uma usuária através de seu modo de produzir cuidado em suas redes de conexões existenciais, mas antes cabe falar um pouco sobre o dispositivo que utilizamos para produzir um território com Frida.

\section{O acompanhamento terapêutico - AT}

Algumas experimentações ocorridas no território através do encontro com o outro é explorado por Lancetti (2006) em seu livro "Clínica Peripatética". Umas das fontes dessa Clínica operada em movimento, fora do consultório, é o Acompanhamento Terapêutico que por si só é peripatética (no sentido etimológico, peritatéó: passear, ir e vir conversando).

0 trabalho de Acompanhamento Terapêutico (AT) surge na Argentina, no final da década de 60 e tem como precursores o movimento da Antipsiquiatria, através das comunidades Terapêuticas, a psiquiatria democrática, a psiquiatria de setor e a análise institucional difundida na Europa e nos Estados Unidos, a partir da década de 50. № Brasil, as ideias da antipsiquiatria começaram a ecoar e surgem as primeiras comunidades terapêuticas em São Paulo, Rio de Janeiro e Porto Alegre (Pitia \& Santos, 2006).

Importante ressaltar a diferenciação entre os primeiros modelos de Comunidade Terapêuticas e as instituições asilares atuais, que fazem uso do mesmo nome, mas se destinam ao tratamento de pessoas que fazem uso abusivo de drogas. As Comunidades Terapêuticas surgem a partir da década de 40, na Inglaterra. Maxwell Jones, a partir de 1959, sistematizou essa experiência que ficou conhecida como uma busca da transformação do hospital psiquiátrico através de um processo de horizontalidade e democratização das relações. Por meio da realização de grupos de discussão e grupos operativos havia uma participação ativa dos pacientes em seus tratamentos, com 0 encorajamento da expressão de sentimentos e a luta por uma organização social, democrática e igualitária (Amarante, 2007).
Nesses locais, os chamados auxiliares psiquiátricos eram jovens universitários que participavam de toda a experiência dos pacientes em seu cotidiano hospitalar. Com o declínio das Comunidades Terapêuticas, esses profissionais continuaram a ser solicitados por familiares e terapeutas que não desejavam a internação, passando então a fazer acompanhamento em domicílio, auxiliando na administração da medicação e nos vínculos com a família. Também já foi chamado de "amigo qualificado", mas esse termo caiu em desuso e foi substituído por acompanhante terapêutico por expressar melhor o trabalho que é realizado por esses profissionais (Londero \& Pacheco, 2006; (haui-Berlinck, 2010).

Ao longo do tempo o AT foi se consolidando como um recurso indicado para 0 tratamento de pessoas em crises psicóticas e em situações de comprometimento psíquico. Porém, atualmente esta prática se aplica a diversos contextos onde há dificuldades de socialização e de desenvolvimento de atividades da vida diária (Chaui-Berlinck, 2010).

Assim, o AT é um trabalho clínico cujo campo de ação é o cotidiano e os espaços de circulação da vida do acompanhado, uma intervenção que busca promover a reinserção social e a autonomia a partir das necessidades e desejos do indivíduo. A atuação se estende para crianças e adolescentes, em escolas, com idosos, pessoas com transtornos mentais, pessoas em uso abusivo de álcool e outras drogas, etc (Chaui-Berlinck, 2010).

As intervenções e estratégias do AT são andarilhas e exigem inventividade, pois devem suscitar a dimensão clínica, política e ético-estética que se desenha na composição de forças que atravessam esse trabalho. Além disso, 0 trabalho do AT se desenvolve a partir do indivíduo através da articulação da sua rede comunitária, possibilitando assim o fortalecimento da rede intersetorial (Silva \& Silva, 2006; Acioli Neto \& Amarante, 2013).

0 trabalho com o Acompanhamento Terapêutico diz de uma clínica antimanicomial, alinhada com os preceitos da Reforma Psiquiátrica. Aqui cabe lembrar Basaglia (1981, como citado em Amarante, 1996) quando nos alerta para o "duplo da doença mental", isto é, ao que não é próprio de estar doente e sim institucionalizado (não apenas em hospitais, mas também nos (APS). Nessa perspectiva, a proposta lançada é que, ao invés do sujeito, a doença seja colocada entre parênteses, não para negar sua existência, mas para que o sujeito possa ser olhado em sua totalidade (Basaglia,1981 como citado em Amarante, 1996).

Corroborando com essa teoria e se opondo ao que postula a psiquiatria tradicional, existem várias pesquisas epidemiológicas atuais que constatam que a cronificação das pessoas com transtorno mental não é algo intrínseco ao sofrimento psíquico. Trata-se de um complexo de variáveis externas ao indivíduo, em geral ligadas a contexto familiar e da comunidade, sendo passíveis de transformação através de um processo de intervenção (Lussi, Pereira \& Pereira, 2006).

Lancetti (2006) afirma que as ações de saúde mental que acontecem no território - geográfico e existencial - são ações complexas e que nesse atravessamento de territórios é preciso fabricar mundos. Ou seja, é preciso também fabricar novas e diversas formas de pensar e produzir o cuidado em saúde. 


\section{Método}

Esse trabalho trata de uma pesquisa-intervenção inspirada na cartografia proposta por Deleuze e Guattari (1995). Numa pesquisa cartográfica é preciso uma imersão no plano da experiência, sem qualquer tipo de neutralidade, pois o conhecer e o fazer se tornam inseparáveis. 0 interesse aqui é muito mais em acompanhar os processos, do que descrever estados de coisas. Para a realização de uma pesquisa cartográfica é preciso a habitação de um território, exigindo um processo de aprendizagem por parte da cartógrafa (Passos \& Barros, 2015).

Na pesquisa cartográfica o conhecimento é construído com e não sobre o campo pesquisado, permitindo-se encontrar o que não estava sendo procurado e deixando-se ser encontrado pelo acontecimento (Alvarez \& Passos, 2015). Essa perspectiva produz desvios sobre o plano macropolítico vinculado à lógica da representação do mundo e operado por ideais que transcendem a experiência viva do acontecimento. Assim, ao buscar o plano intensivo dos encontros, acessa o fluxo micropolítico dos afetos a partir dos processos em curso que dizem respeito às forças de diferentes naturezas em jogo na produção das territorialidades que tais encontros são capazes de produzir. Em outras palavras, a cartografia põe o pesquisador numa posição ética-estética e política cuja potência produz novos agenciamentos a partir das conexões que só 0 plano micropolítico pode fazer passar. Não se trata, portanto, de uma análise compreensiva/interpretativa da experiência, mas de uma análise esquizo que recusa a reificação do mesmo para se lançar na criação de singularidades a partir das experimentações produzidas pelos encontros.

A micropolítica autoriza a não tomar a vida como um bonsai, a ser disciplinado, educado ou curado. Permite-nos reafirmar sua existência-rizoma. Em lugar de mostrar o caminho, dar força a essa vida que pede passagem. Seguirá ela imprevisível como 0 curso de um rio (Rossotti \& Bicalho, 2012. p. 95).

Sendo assim, a pesquisa cartográfica, enquanto uma pesquisa-intervenção se propõe a acompanhar processos, os fluxos do território onde se produzem. Essa processualidade também se apresenta diante dos dados, não havendo uma separação entre coleta, análise e discussão dos dados, ou seja, são passos que caminham juntos na cartografia (Barros \& Kastrup, 2015).

0 trabalho da cartógrafa não consiste em coletar dados, mas sim em produzi-los através da imersão na experiência no território, assumindo assim um lugar ativo, tanto da pesquisadora quanto dos pesquisados. Diante disso, essa experiência se deu a partir de encontros fixos e periódicos que aconteciam uma vez por semana, às vezes duas, às vezes nenhuma.

Durante todo o tempo de imersão no território, foi produzido o diário de campo cujas anotaç̃̃es subsidiaram a produção de dados. Esse registro tem a função de transformar as observações de campo, rastreando o que se dá no plano intensivo de forças e afetos. Essa experiência se transforma em conhecimento e vice-versa, sinalizando também modos de se fazer (Barros \& Kastrup, 2015).

Importante destacar que toda teoria é sempre cartografia, e isso quer dizer que ela vai se fazendo ao mesmo tempo em que acompanha os processos no campo. Assim, tudo o que dá passagem aos movimentos do desejo, tudo o que servir para criar matéria de expressão e sentido, é bem-vindo para a cartografia.
Nesse sentido, a busca e 0 uso das fontes são variados e podem incluir não só teorias e nem só escritos, mas tudo aquilo que favorece a expressão de linguagem que sirva para dar passagem às intensidades que percorrem e afetam o corpo da cartógrafa no encontro com outros corpos. "Seus operadores conceituais podem surgir tanto de um filme quanto de uma conversa ou de um tratado de filosofia". Assim, a cartógrafa é também uma antropófaga: se dedica a expropriar, se apropriar e devorar múltiplas matérias que sirvam para compor a sua cartografia (Rolnik, 2016).

A noção de entendimento da cartografia não se aproxima de explicar tampouco de revelar. Parte da ideia do que existe em cima, nos lados e embaixo são intensidades buscando expressão. A cartografia quer merguIhar no campo dos afetos, inventando pontes para essa travessia, através da linguagem (Rolnik, 2016).

Nesse sentido, podemos pensar que o problema para a cartografia não é alicerçado na ideia de falso-ou-verdadeiro, nem o do teórico-ou-empírico, mas na ideia de que temos um vitalizante-ou-destrutivo, ativo-ou-reativo. A cartógrafa quer então embarcar nesses territórios, na realidade. Ao se pensar quais seriam então os procedimentos para a cartografia, podemos afirmar que estes pouco importam, pois se sabe que deve inventar, a partir do que 0 contexto em que se encontra e o que o mesmo pede, não se seguindo nenhum protocolo formal e pré-datado de pesquisa (Rolnik, 2016).

A prática política da cartógrafa tem a ver com o exercício de facilitar a passagem das intensidades que emergem nos encontros ao longo da vida. Está ligada às estratégias das formações do desejo no campo social, às escoIhas de como viver. É uma prática que atua pela via da expansão do alcance do desejo enquanto produtor de novos e diversos mundos, novas e diversas sociedades (Rolnik, 2016).

A referida pesquisa foi aprovada pelo Comitê de Ética em Pesquisas com Seres Humanos da Universidade de Pernambuco - REITORIA - UPE, sob o CAAE: 19356019.6.0000.5207, sendo obedecidas todas as orientações da Resolução no 466/2012 do Conselho Nacional de Saúde. Além disso, a participante assinou o Termo de Consentimento Livre e Esclarecido (TCLE) de acordo com a resolução 466/12, para participação na pesquisa.

\section{Resultados e discussões}

Os encontros entre a cartógrafa e Frida ocorreram, quase sempre, em praças públicas em contato com a natureza, às vezes sentadas na grama ou num banquinho qualquer debaixo da sombra de uma árvore. E esse foi 0 nosso principal palco para que a palavra circulasse entre nós e onde ela quis lembrar do seu passado, pensar sobre ele no presente e seguimos juntas no presente sem saber o que esses encontros gerariam entre nós.

0 Acompanhamento Terapêutico é, em essência, uma prática itinerante realizada em movimento, onde os atendimentos, frutos de uma escuta clínica, variam desde espaços privados como uma casa, um quarto, uma cozinha, quanto em espaços públicos como o consultório, o banco, a igreja, praça, etc. Além disso, trata-se de estabelecer uma rede de relações que vão além da usuária, abarcando também sua família, pessoas do seu convivio social, ou seja, a sua rede de relação existencial. (Alberti, Teixeira, Beteille, Wan Der Maas Rodrigues, \& Martinez, 2017).

Infelizmente o contato com a família de Frida não foi possível de ser feito até 0 momento de finalizar o processo de escrita sobre essa cartografía. Isso 
se deu tanto pelo fato dela morar sozinha, como também de seus familiares morarem no interior da Paraíba o que torna essa relação entre eles ainda mais distante.

Importante ressaltar aqui que o AT foi tomado como um disparador que funcionasse com um duplo objetivo: sendo tanto um ampliador das possibilidades de vida de Frida ao mesmo tempo que possibilitasse a reflexão sobre a produção do cuidado através das redes não institucionalizadas. No momento dos nossos encontros, ela havia optado por não continuar sendo atendida no Centro de Atenção Psicossocial o qual estava vinculada, por não se adequar às oficinas que lhe foram oferecidas. Ressaltamos aqui que a produção de redes vivas de Frida aconteceram também em paralelo ao seu acesso aos serviços de saúde do SUS. Constituem-se, pois, como uma rede rizomática que se monta e se desmonta, ramificada em várias conexões, com múltiplas entradas e saídas, com suas linhas de fuga (Deleuze \& Guattari, 1995).

Entendemos que a produção de redes vivas é rizomática, está se produzindo através de conexões, da potência dos encontros. Podemos também usar a filosofia de Espinosa para pensar como as redes vão sendo tecidas por cada pessoa na busca de seu cuidado. 0 encontro de corpos e de ideias pode ser considerado bom ou ruim. Um mau encontro é aquele em que um corpo ou uma ideia não se compõe com outro corpo, tornando-o mais fraco, diminuindo ou até destruindo a potência de agir. 0 bom encontro, ao contrário, é aquele que funciona como alimento e se compõe com o outro corpo, aumentando nossa potência de existir, agir e pensar (Deleuze, 2002).

0 conceito de conatus é definido por Espinosa como o esforço para perseverar na existência, transpor os obstáculos externos e também alcançar o desenvolvimento e realização o mais plenamente possível (Deleuze, 2002). A essência do conatus é, pois, a busca por bons encontros e a evitação de maus encontros. Para Deleuze (2002) esse conceito é como a potência de agir, a busca por experimentar a alegria e exorcizar a tristeza. Arrisco-me então a dizer que a produção de redes vivas é a busca pela ampliação da potência de agir, através dos furos que cada um consegue ir fazendo diante da vida.

Frida escreve. Diz que quer escrever um livro contando sua história e que já tem vários papéis escritos, desordenados, soltos e espalhados, com erros de português e sem uma cronologia. Escreve sua história, seus pensamentos, seus desejos para se sentir um pouco aliviada. Deu-me alguns. 0 que achei mais interessante foi uma lista de 17 assuntos que ela queria poder falar ao longo dos nossos encontros e, então, superar. Estes tratam desde sua infância até suas relações atuais, ela localizou suas dores, seus traumas e suas dificuldades comportamentais. Em outro texto fala do desejo de poder superar tudo logo, mas reconhece que não funciona assim tão simples, fácil ou rápido.

Em um de nossos últimos encontros me surpreende dizendo que começou a escrever seu livro. Criou um documento online onde já escreveu alguns fatos que lhe aconteceram e até agora são todos os fatos tristes. Pediu meu e-mail e compartilhou comigo para que eu pudesse ir acompanhando todos seus escritos, me autorizando a fazer correções no texto que o ajudem a deixar mais coerente. Fiz a sugestão de que ela pensasse também sobre suas histórias alegres e escrevesse, pois estas também faziam parte de sua vida e muitas vezes ela não conseguia lembrar quando estava na fase depressiva. Sua resposta foi de que ainda irá escrever sobre as coisas boas de sua vida, mas ainda não era a hora, não naquele momento.

Além da descoberta da escrita como meio de dar vazão aos seus pensamentos e sentimentos, outro movimento interessante de Frida foi a de levar alegria às crianças com câncer em um hospital público. Junto com seus irmãos, se vestia de palhaça e iam juntos arrancar sorrisos de quem estivesse na ala infantil oncológica.

Contou sobre essa experiência com muita alegria, mostrou fotos dos figurinos e alguns vídeos junto com seus irmãos. Explicou que para ser paIhaça tem que ter certo dom para o humor, não é todo mundo que consegue. Ensaiavam algumas músicas, mas na hora acabavam improvisando tudo. Foi uma experiência curta, de dois meses, mas muito potente e que a mobilizou afetivamente diante da produção de alegria, esquecendo por aqueles instantes as suas tristezas, mas talvez extraindo daí mesmo a força para fazer graça. Em uma de nossas conversas em que ela estava se sentindo inútil e que não sabia fazer nada, eu soltei" ué, mas você já foi até palhaça! Não é todo mundo que sabe ser palhaça né?" E rimos juntas.

Além de produzir alegria, Frida também já produziu cuidado. Trabalhou desde adolescente em algumas casas como babá de crianças pequenas e ajudando no serviço doméstico. Em uma das últimas casas já havia sido curatelada, mas durante a troca entre os curadores passou um tempo sem receber a aposentadoria, foi com esse trabalho que conseguiu se sustentar nesse meio tempo. Vez ou outra se lembra desse trabalho, das crianças, dos seus patrões e do apoio que deram durante suas crises.

Desses bons encontros que surge na vida, Frida conheceu uma pessoa que a levou para participar de uma palestra em um centro espírita. Desde então tem frequentado reuniões e ampliado sua rede de contatos e cuidado através da espiritualidade. Nesse lugar se sente pertencente e se refere como um espaço onde conseguiu construir uma família.

Através dessa mesma amiga, que a levou ao centro espírita, conheceu o grupo de ajuda mútua voltado a pessoas com o diagnóstico de TAB. Nesse espaço dizia que se sentia muito à vontade para compartilhar sua história e ficava incomodada quando as outras pessoas referiam-se a ela como um exemplo ou inspiração. 0 seu incômodo se dava porque ela não conseguia enxergar-se assim, as suas marcas de vida distorciam a percepção sobre si, enxergando apenas uma Frida triste, inútil e incapaz.

Através do Grupo de Apoio Mútuo, também teve acesso a outros profissionais que atuavam fora da rede de saúde formal, a exemplo de sua psiquiatra e de uma fisioterapeuta que lhe oferecia sessões de acupuntura para aumentar a mobilidade do braço e evitar que atrofiasse ainda mais. Também aqui me incluo, pois foi através desse grupo que nos encontramos. Assim, Frida formou sua própria equipe de profissionais particulares: psiquiatra, fisioterapeuta e psicóloga/acompanhante terapêutica.

A sua participação no GAM também a levou a outro lugar: começou a frequentar um coral onde algumas pessoas do grupo também participavam. Fez 0 teste de voz e descobriu que alcança duas classificações vocais e foi elogiada pelo professor. Inclusive já se apresentaram ao público em um teatro da cidade.

Um dos efeitos produzidos nesses nossos encontros através do AT foi o de pensar sobre o seu cuidado, quais tratamentos, quais profissionais, a interação dos medicamentos, o efeito desses no seu corpo, quando pede ajuda, quando se afasta daquilo que não a faz bem... Em uma de nossas primeiras conversas, quando ela me falava sobre o seu uso da maconha, comentei também sobre os efeitos terapêuticos da planta e também do trabalho da Associação Brasileira de Apoio à Cannabis Esperança ( $A B R A C E$ ) aqui da Paraíba que produz o óleo canábico. Ela me ouviu com atenção, mas não pareceu dar tanta importância. 
Um tempo depois ela comentou que conversou com sua psiquiatra sobre, e, a princípio, a profissional pareceu pouco motivada em receitar o óleo. Embora a médica nunca tenha desaconselhado Frida a interromper o uso da cannabis, pois percebia os ganhos que isso trazia para seu bem-estar, pediu que limitasse o uso para que o excesso não fosse prejudicial.

Minha surpresa foi receber uma mensagem de Frida perguntando se eu poderia ir com ela comprar o óleo da cannabis que a psiquiatra havia receitado. Combinamos o dia e fomos juntas de ônibus até o local onde trabalhava a pessoa que iria vender o óleo. Nesse percurso Frida me conta que tentar esse tratamento só foi possível depois que ela ouviu de mim que ele existia e que estava empolgada para que desse certo e conseguisse ficar mais estabilizada.

Na volta conversamos sobre seu aniversário que seria naquela semana e seu conflito entre a vontade de comemorar experimentando tomar chopp pela primeira vez e de não poder ingerir álcool pela quantidade de remédios que tomava. Ela me fala de que nunca consegue beber pouco e por isso achava que não iria beber, mas insistia na vontade de tomar chopp. Negociamos a quantidade, digo que ela poderia tomar no máximo 2 chopps por ser seu aniversário. Ela fala que a médica irá reclamar, e eu respondo que ela pode dizer que eu a autorizei, mas apenas dois chopps e nada mais que isso. Ela sorri satisfeita como se eu estivesse dando a ela um presente. Depois quando nos encontramos, após seu aniversário, conta que bebeu só um chopp e não gostou. Falou para a psiquiatra que só bebeu porque eu tinha liberado e que a médica riu dizendo que tinha sido um acordo justo considerando que era o seu aniversário.

Tenho certeza que Frida beberia aquele chopp, com minha suposta autorização ou não. Negociar a quantidade com ela, percebendo que ela entendia os riscos da interação com a medicação (afinal esse era o seu conflito) foi talvez um ato de liberação e responsabilização ao mesmo tempo. Liberação da culpa que ela sentiria após beber, pois sempre me dizia que é assim que se sente quando acaba consumindo bebidas al cóolicas. Responsabilização do cuidado de si mesma, ao entender que ela podia beber sem culpa, mas com a moderação necessária.

Através do AT foi possível ir acompanhando o rastro da composição de sua rede existencial. Frida foi criando conexões que a levaram a outras: reuniões no centro espírita; participação no grupo de apoio mútuo voltado a pessoas que tinham o mesmo diagnóstico que ela; através da amizade desse grupo começou a participar de um coral; e também formou sua equipe de profissionais particulares que caminham com ela nesse processo de cuidado, com seus altos e baixos.

\section{Conclusão}

0 Acompanhamento Terapêutico pode ser um grande aliado para dar visibilidade e dizibilidade a outras formas de ser e existir, apesar dos estigmas que carregam as pessoas com um diagnóstico psiquiátrico. Enxergar a produção das redes vivas dos sujeitos nos diz também do tanto de potência de vida que se pode produzir onde, talvez, nós não conseguíssemos enxergar por estarmos apenas do lado de dentro dos muros institucionais. Cartografar o processo de cuidado na saúde mental pode nos ajudar a exercitar o olhar para outros modos de sofrimento que não estão atrelados somente a um CID. Além da possibilidade de ampliar e fortalecer os recursos que cada um vai criando no processo de cuidado de si.
Através do que Frida nos apontava, fomos articulando seu cuidado na rede de profissionais que ela escolheu. Nossa postura não poderia ser diferente, afinal não nos propusemos a estar numa relação de superioridade de saber, quem estava produzindo o seu próprio cuidado era Frida, que nos permitiu acompanha-la nessa trajetória. Da mesma forma, nossa disponibilidade em procurar informações sobre direitos em relação à sua curatela e aposentadoria foram dispensados por ela, pedindo isso explicitamente, pois afirmou que não gostaria de adentrar nessas questões naquele momento.

Outro ponto a se frisar é que lançar o olhar para a produção das redes vivas de cuidado não se trata de desqualificar as redes de saúde institucionalizadas. Perceber essas linhas que operam nos furos da rede é fundamental para renovar o nosso fazer em saúde, qualificando e fortalecendo esse cuidado. Mais ainda, possibilitar que o encontro entre a rede formal e a rede viva seja um ampliador da potência de vida.

Nesse caso acompanhado, a Rede de Saúde Mental não conseguiu sustentar e articular devidamente o cuidado para estar ao lado de Frida como a complexidade do seu caso exigiria. Além das dificuldades clínicas do próprio transtorno em que certa estabilização ainda é muito difícil, soma-se a isso outras marcas: ser mulher, bissexual, pessoa com deficiência e vítima recorrente de violência sexual e psicológica, desde infância inclusive.

Como preparar os profissionais de saúde para enxergar além de um CID? Como operar na lógica de colocar a doença entre parênteses e olhar o sujeito em suas múltiplas dimensões? Uma pista inicial, talvez seja a de ir rastreando a produção de vida dos sujeitos, quais as ferramentas que 0 usuário utiliza para produzir seu cuidado... e então, produzir um cuidado intercessor em que os saberes técnicos se alinhem e se misturem aos saberes do usuário. Mas para isso é preciso estar atento e sensível ao que o outro traz, aos modos de existir e também perceber como os impactos das mudanças sociais reverberam nos sujeitos.

Importante percebermos o quanto que a produção de vida dos usuários escapa aos olhares na rede de saúde mental e se invisibiliza dentro dos CAPS. Daía importância de construir Projetos Terapêuticos Singulares, principalmente para os casos mais complexos. Claro que nem todos os usuários de um serviço demandarão tantos cuidados e articulações com outras redes, é para isso que o conceito de equidade deve estar sempre presente também nas reuniões de equipe para discussão de casos.

Retomamos o que Lancetti (2006) nos sinalizou ao falar de CAPS turbinado, a complexidade de um caso deve instigar o serviço a realizar múltiplas articulações, com outras redes para que o cuidado seja realizado integralmente. Isso demanda também disponibilidade e inventividade.

Essas reflexões não se tratam de uma crítica que nega a importância da Reforma Psiquiátrica e seus avanços. Trata-se de exercitar o olhar, o pensar e 0 agir sobre nossas práticas num exercício de fortalecimento do processo de cuidar. Aliás, colocar em análise as nossas ações, as nossas implicações é uma das lógicas da educação permanente que compõe as práticas em saúde.

E aqui se faz a defesa de que mais que a necessidade de termos na rede de saúde um profissional de AT, devemos exercitar a função de Acompanhante Terapêutica nos serviços públicos de saúde/saúde mental. Ou seja, extrair daquilo que o AT nos convoca a sair dos muros institucionais; a estar disponível ao encontro com um outro; a exercitar nossa capacidade criativa de cuidar do outro, com o outro, no mundo dele. A aposta é desse cuidado, um devir-cuidado. 
Assim, ressaltamos a imperiosa urgência em criarmos cada vez mais estratégias e ações de produção de cuidado que estejam cada vez mais conectadas com uma produção de vida autônoma, potente e em liberdade. Que continuemos operando no dia a dia os princípios da Luta Antimanicomial, da Reforma Psiquiátrica, mas não qualquer uma, e sim uma Reforma Psiquiátrica Antimanicomial.

\section{Referências}

Alberti, S., Teixeira, L. C., Beteille, I. M, Wan Der Maas Rodrigues, S., \& Martinez, C.R. B. de S. (2017). 0 Acompanhamento Terapêutico e a psicanálise: pequeno histórico e caso clínico. Revista Latinoamericana de Psicopatologia Fundamental, 20(1), 128-141. Doi: https://doi.or$\mathrm{g} / 10.1590 / 1415-4714.2017 \mathrm{v} 20 n 1 \mathrm{p} 128.9$

Acioli Neto, M. L., \& Amarante, P. D. C. (2013). 0 acompanhamento terapêutico como estratégia de cuidado na atenção psicossocial. Psicol. cienc. prof., Brasília, v. 33, n. 4, p. 964-975. https://doi.org/10.1590/S141498932013000400014

Alvarez, J., \& Passos, E. (2015). Cartografar éacompanhar processos. In Passos, E., Kastrup, V., \& Escóssia, L. Pistas do método da cartografia: Pesquisa-intervenção e produção de subjetividade (pp. 131-149). Porto Alegre: Sulina.

Amarante, P. (1996). O homem e a serpente: outras histórias para a loucura e a psiquiatria. Rio de Janeiro. Fiocruz.

Amarante, P. (2007). Saúde Mental e Atenção Psicossocial. Rio de Janeiro. Editora fiocruz.

Barros, L. P., \& Kastrup, V. (2015). Cartografar é acompanhar processos. In Passos, E., Kastrup, V., \& Escóssia, L. Pistas do método da cartografia: Pesquisa-intervenção e produção de subjetividade (pp. 52-75). Porto Alegre: Sulina.

Chaui-Berlinck, L. (2010). 0 acompanhamento terapêutico e a formação do psicólogo: por uma saúde humanizada. Arq. bras. psicol. [on line]. vol.62, n.1, pp. 90-96. ISSN 1809-5267. Recuperado de: http://pepsic.bvsalud.org/scielo.php?script=sci_arttext\&pi$\mathrm{d}=$ S1809-52672010000100010\&lng=pt\&ting=pt.

Deleuze, G., \& Guattari, F. (1995). Mil platôs: capitalismo e esquizofrenia. Vol. 1. Ed. 34.

Deleuze, G. (2002). Espinosa - Filosofia prática. Tradução: Daniel Lins e Fabien Pascal Lins. Ed. Escuta.

Lancetti, A. (2006). Clínica Peripatética. Hucitec.

Londero, I., \& Pacheco, J. T. B. (2006). Por que encaminhar ao acompanhante terapêutico? uma discussão considerando a perspectiva de psicólogos e psiquiatras. Psicol. estud., Maringá, v. 11, n. 2, p. 259-267. http://dx.doi. org/10.1590/\$1413-73722006000200004.

Lussi, I. A. 0., Pereira, M. A. 0., \& Pereira, J. A. (2006). A proposta de reabilitação psicossocial de Saraceno: um modelo de auto-organização? Revista Latino-Americana de Enfermagem, 14(3), 448-456. https://doi.org/10.1590/ S0104-11692006000300021

Merhy, E. E. (2004). 0 ato de cuidar: a alma dos serviços de saúde. In: BRASIL. Ministério da Saúde. Secretaria de Gestão do Trabalho e Educação na Saúde. Departamento de Gestão da Educação na Saúde. Ver-SuS Brasil: caderno de textos. Brasília: Ministério da Saúde, p.108-137. Recuperado de: https:// www.nescon.medicina.ufmg.br/biblioteca/registro/0_ato_de_cuidar_a_alma_dos_servicos_de_saude/59
Merhy, E. E., Gomes, M. P. C., Silva, E., Santos, M. F. L. Cruz, K. T., \& Franco T. B. (2014). Redes Vivas: multiplicidades girando as existências, sinais da rua. Implicações para a produção do cuidado e a produção do conhecimento em saúde. Saúde para Debate. n. 52, p. 153-164. Recuperado de: https://www. researchgate.net/publication/305808534_Redes_Vivas_multiplicidades_girando_as_existencias_sinais_da_rua_Implicacoes_para_a_ producao_do_cuidado_e_a_producao_do_conhecimento_em_saude

Passos, E., \& Barros, B. R. (2015). A cartografia como método de pesquisa-intervenção. In Passos, E., Kastrup, V., \& Escóssia, L. Pistas do método da cartografia: Pesquisa-intervenção e produção de subjetividade (pp. 17-31). Porto Alegre: Sulina.

Pitia, A. C. A., \& Santos, M. A. (2006). 0 acompanhamento terapêutico como estratégia de continência do sofrimento psíquico. SMAD, Rev. Eletrônica Saúde Mental Álcool Drog. (Ed. port.) [on line]. vol.2, n.2, pp. 0-0. ISSN 1806-6976. Recuperado de: http://pepsic.bvsalud.org/scielo.php?script=sci_arttext\&pid=S1806-69762006000200008

Rolnik, S. (2016). Cartografia sentimental: transformações contemporâneas do desejo. 2 ed. Porto Alegre: Sulina/Editora da UFRGS.

Rossoti, B.G., \& Bicalho, P.P. G. (2012). Por outra Psicologia no Cárcere: Presos provisórios, processos de criminalização e produção de subjetividade. In: Reflexões experiências em Psicologia Jurídica: no contexto criminal/penal.1 ed. São Paulo: Vetor, v.1, p. 81-108.

Silva, A. S.T., \& Silva, R. N. (2006). A emergência do acompanhamento terapêutico e as políticas de saúde mental. Psicol. cienc. prof., Brasília, v. 26, n. 2, p. 210-221, jun. https://doi.org/10.1590/S1414-98932006000200005. 